\title{
Mars MOURA magnetometer demonstration for high-resolution mapping on terrestrial analogues
}

\author{
Marina Díaz-Michelena ${ }^{1}$, Rolf Kilian ${ }^{2,3}$, Ruy Sanz ${ }^{1}$, Francisco Rios ${ }^{2}$, and Oscar Baeza ${ }^{2}$ \\ ${ }^{1}$ Payloads and Space Sciences Department, INTA, Ctra. Torrejón - Ajalvir km 4, 28850 Torrejón de Ardoz, Spain \\ ${ }^{2}$ Geology Department, University of Trier, Behringstrasse, 54286 Trier, Germany \\ ${ }^{3}$ University of Magellanes, Punta Arenas, Chile \\ Correspondence to: Marina Díaz-Michelena (diazma@inta.es)
}

Received: 27 November 2015 - Published in Geosci. Instrum. Method. Data Syst. Discuss.: 1 February 2016

Revised: 11 April 2016 - Accepted: 12 April 2016 - Published: 19 May 2016

\begin{abstract}
Satellite-based magnetic measurements of Mars indicate complex and very strong magnetic anomalies, which led to an intensive and long-lasting discussion about their possible origin. To make some progress in the investigation of the origin of these anomalies the MOURA vector magnetometer was developed for in situ measurements on Mars. In this work we propose the utilisation of such an instrument for future planetary on-ground surveys. The proof of its suitability is seen through testing it on various terrestrial analogues characterised by the distinct magnetic anomalies of their basement rocks: (1) a magnetite body of EL Laco (up to $+110000 \mathrm{nT})$ and its transition to surrounding andesites $(<+2000 \mathrm{nT})$ in the northern Andes of Chile showing the highest local magnetic anomalies. The magnetite-bearing ore body has highly variable local anomalies due to its complex formation history where a significant dispersion in palaeoorientations has been previously reported, while our vector data show relatively uniform and probably induced declinations. (2) A basaltic spatter cone of the Pali Aike volcanic field, in southern Chile, was characterised by very strong magnetic anomalies along the crater rim (up to $+12000 \mathrm{nT}$ ), controlled by the amount of single domain magnetites in the ground mass of the basalts. Due to their strong remanent signature, palaeo-declinations of the lavas and reorientations of collapsed blocks could be constrained by the vector data. (3) The Monturaqui meteorite crater (350 m diameter), in northern Chile, shows significant variations of its anomalies (from -2000 to $>+6000 \mathrm{nT}$ ) in restricted areas of several square metres along its crater rim related to unexposed iron-bearing fragments of the impactor while its granitic and ignimbritic target rocks exhibit only very weak anoma-
\end{abstract}

lies. (4) An area with several amphibolitic dykes, which cross-cut a Cretaceous granitoid in the southernmost Andes, where a decimetre-scale mapping was performed. In this case, pyrrhotite is the only magnetic carrier. It was formed during hydrothermal processes within the dykes. Very low $(+40$ to $+120 \mathrm{nT})$ positive magnetic anomalies clearly depict the amount of $1-4 \mathrm{vol} \%$ pyrrhotite in these dykes, which is important as a mineralogical indicator as well as to detect associated gold and copper enrichment.

\section{Introduction}

Mars' magnetic field has been exhaustively measured between 100 and $440 \mathrm{~km}$ altitude by Mars Global Surveyor (Acuña et al., 1998; Connerney et al., 2005; Morschhauser et al., 2014). These data show that the magnetic anomalies of the martian crust are up to 20 times higher than those of the Earth (Scott and Fuller, 2004). However, a profound understanding of the magnetic signature of the martian crust would require mapping at different altitudes and consequently with a different magnetic zoom apart from further petrological analyses. Since Mars presents a very low dense atmosphere, aeromagnetic surveys are not achievable in the short term. Thus, on-ground magnetometry with landers and rovers seems to be the most immediate feasible technology to complement the satellite measurements. The MOURA magnetometer was developed by Instituto Nacional Técnica Aerospacial (INTA) in the context of MetNet Precursor Mission to perform vector magnetometry and gradiometry during on-ground surveys prior to rover-based surveys on 
extraterrestrial planets, such as Mars. The instrument has a very low mass $(72 \mathrm{~g})$, a scalable range, high precision, low detectable fields and noise, and is capable of working in the very hard environmental conditions of Mars. Diaz-Michelena et al. (2015a) describes the MOURA's main technical details, the calibration, as well as a demonstration on how to measure the absolute magnetic field and its temporal variations.

The first objective of the present work is to demonstrate the capability of the miniaturized MOURA instrument in a real context of terrestrial analogue surveys by means of the intercomparison with the data of a scalar caesium reference magnetometer (Diaz-Michelena and Kilian, 2013). To do this, four different sites with a wide variability in the intensity of their magnetic signatures have been selected. A second objective is the magnetic investigation of these sites and their implication as terrestrial analogues of Mars. A further objective is the potential of high-resolution mapping to show the lowest magnetic contrasts in the terrain and their correlation with the distinct magnetic carriers responsible for their signatures (Acuña et al., 1998; Connerney et al., 2005; Lillis et al., 2013).

Our selected sites include magnetic anomalies from complex geological environments, where, e.g., noise factors, geometrical characteristics of non-exposed rock units and effects of the terrain relief can partly obscure the interpretations concerning the kind and magnetic effects of non-exposed rock units. Thus, a modelling of the magnetic anomalies is desirable in general to improve the interpretation of geometrical and compositional effects of non-exposed rocks (e.g. Eppelbaum, 2015; Eppelbaum and Mishne, 2011; Ialongo et al., 2014). Since we are aware of the problematics, primarily we focus on the interpretation of the effects of distinct types and compositions of exposed rocks concerning the observed magnetic anomalies. Future more detailed studies of the investigated sites should include the above-mentioned magnetic modelling, which is outside the scope of this magnetometer demonstration.

\section{Methodology}

\subsection{Magnetic instrumentation}

Two different magnetometers have been used for the present surveys: a conventional caesium scalar magnetometer: model G-858 MagMapper by Geometrics and the MOURA vector magnetometer designed and developed by INTA MetNet team for Mars exploration.

G-858 is taken as the reference magnetometer because it is a well-established hand-held instrument $(8-9 \mathrm{~kg})$ for magnetic surveys (ordnance, archaeology, environmental, mineralogy, and petroleum prospection). It has $8 \mathrm{~h}$ autonomy, provides a suitable contrast related to magnetic anomalies $(8 \mathrm{pT} / \sqrt{ } \mathrm{Hz})$ and good stability covering the range of the Earth magnetic field with a dynamic range between 20000 to $100000 \mathrm{nT}$. It also has several modes of operation: continuous and discrete to allow users to plan the prospections grids. In contrast to the MOURA, this magnetometer only provides the intensity of the total magnetic field, its performance is dependent on the orientation of the head with respect to the field, which changes significantly in the latitude range of the present survey, and it is restricted to areas with gradients higher than $20000 \mathrm{nTm}^{-1}$ (Table 1).

The MOURA is a vector magnetometer with two threeaxes magnetic sensors of anisotropic magnetoresistance (AMR) by Honeywell to build up a compact and miniaturized instrument $\left(72 \mathrm{~g}\right.$ mass and $\left.67.5 \mathrm{~cm}^{3}\right)$ for Mars exploration. The power consumption is limited to $400-430 \mathrm{~mW}$, so it can operate more than $10 \mathrm{~h}$ with commercial batteries and poses an insignificant increase of weight to the user $(3 \times 25 \mathrm{~g})$. The instrument is also designed for continuous or discrete modes of operation, it can work in every orientation with no incidence in the performance, and it is practically immune to gradients due to the small size of the transducer ( $\mu \mathrm{m}$-size).

The characteristics are designed for Mars' surface environment ( -90 to $+20^{\circ} \mathrm{C}$ in operation, -120 to $+125^{\circ} \mathrm{C}$ in storage, and a total irradiance dose of $15 \mathrm{krad} \mathrm{s}^{-1}$ ). The resolution is limited by the transducer $(0.2 \mathrm{nT})$ and the range is adapted to that of the Earth geomagnetic field $\pm 65000 \mathrm{nT}$ with an extended range in the auto-offset compensation mode of $\pm 130000 \mathrm{nT}$ (Table 1; Diaz-Michelena et al., 2015a).

\subsection{Track performance}

The tracks have been defined to cover most of the relevant geological features of the selected areas. Continuous and discrete modes have been selected depending on the characteristics and heterogeneity of the sites. For example, the continuous mode has been applied in extended areas in order to have more flexibility and speed to move. In areas with very smallscale heterogeneities the discrete mode has been preferred. In these cases between 5 and 7 measurements have been taken and averaged per point. An advantage of this mode is that it can be measured directly on-ground or at a fixed distance above ground.

The positions of measuring points and tracks have been georeferenced by a Garmin 62s GPS. The GPS tracks have been used to derive the orientation. For some relatively small mapping areas, like the Bahía Glacier (site 4; Fig. 1), a grid of $20 \mathrm{~m} \times 20 \mathrm{~m}$ was previously defined by a tape measure since the error of GPS positions could be of the order of several metres. In these cases, the lines have been used for the orientation.

It has to be taken into account that the different data have been obtained from multiple instruments individually without an automatic synchronism. Therefore, all the acquisition units have been manually synchronised, and the sequence of measurement has been achieved systematically as follows:

1. marking selected measurement point; 
Table 1. Summary comparison between the MOURA and Geometrics 858 magnetometers.

\begin{tabular}{|c|c|c|}
\hline \multirow[t]{2}{*}{ Sensor } & Scalar magnetometer Geometrics 858 & Vector MOURA magnetometer \\
\hline & Scalar sensor and absolute & Two three-axis magnetic sensor \\
\hline Dynamic range & $20000-100000 \mathrm{nT}$ & $\pm 65500 \mathrm{nT}( \pm 130000 \mathrm{nT}$, autorange mode $)$ \\
\hline Resolution & $30 \mathrm{pT}$ & $0.2 \mathrm{nT}$ \\
\hline Cycle rate & $0.1 \mathrm{~s}^{-1} \mathrm{~h}$ & s \\
\hline Gradient tolerance & $>20000 \mathrm{nTm}^{-1}$ & $\sim 1000000 \mathrm{nTm}^{-1}$ \\
\hline Temperature drift & $<0.05 \mathrm{nT}^{\circ} \mathrm{C}$ & $\begin{array}{l}(3.7-6.5) \times 10^{-6} \% \text { in gain }(2.0-7.9) \times 10^{-6} \% \text { in offset } \\
\text { depending on the axis (Diaz-Michelena et al., 2015a) }\end{array}$ \\
\hline Working mode & Continuous and discrete mode & Continuous and discrete mode \\
\hline
\end{tabular}

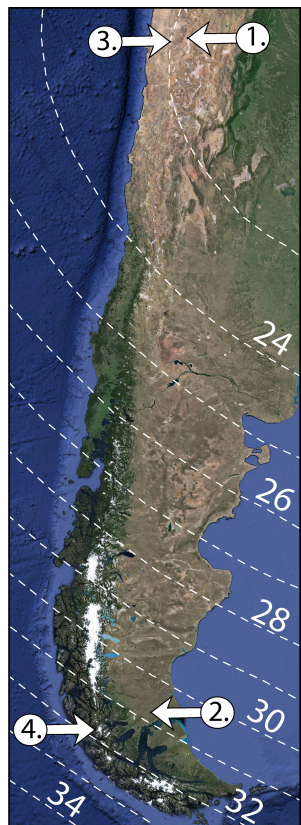

Figure 1. Selected sites: 1 - El Laco, 2 - Pali Aike, 3 - Monturaqui, and 4 - Bahía Glaciers located in South America between latitudes 20 and $52^{\circ} \mathrm{S}$. The white stippled lines indicates isolines for intensities (in $\mathrm{nT} \times 10^{3}$ ) of the International Geomagnetic Reference field ranging from 23000 to $32000 \mathrm{nT}$ at the different sites.

2. GPS measurement with time stamp (with $>6$ satellites at direct sight);

3. removal of the GPS from measurement point to avoid magnetic contamination by this device;

4. magnetic measurement with time stamp (for G-858);

5. magnetometer (three axes), accelerometer (three axes), temperature measurement with time stamp (for the MOURA).

The data files have been pre-processed manually (preliminary corrections of the GPS data with the above-described information). Ad hoc software has been performed to include the temperature and tilt angle correction of the MOURA data, to subtract the Earth geomagnetic field with respect to total intensities in the case of G-858 and each vector component in the case of the MOURA, and to plot the different magnitudes of the processed data.

Local magnetic field anomalies have been calculated with respect to the International Geomagnetic Reference Field (IGRF) averaged for the month of the surveys. At single sites the surveys were performed during less than $2 \mathrm{~h}$ for which global magnetic field data from a base station and/or from the next magnetic observatories with minute resolution have been considered for reference (Argentine Islands near Antarctic Peninsula, Port Stanley, Easter Island and Huancayo $\sim 1400 \mathrm{~km}$ ). However, since temporal variations during all survey intervals of single sites were less than $\pm 10 \mathrm{nT}$ (quiet days), site specific data corrections have not been applied.

In all the surveys, the correlation parameters between the scalar data of the two magnetometers (G-858 and MOURA) as well as between the vector data of the two separate sensors of the MOURA have been systematically calculated.

\subsection{Selected sites: mineralogical and geological context}

The selected test sites for the on-ground survey are situated in or near the southern Andes between latitudes 20 and $52^{\circ} \mathrm{S}$ (Fig. 1).

Required general site characteristics are that (a) exposed rocks are relatively unaltered, (b) high-resolution grids with scales of metres to centimetres can be performed, and (c) exposed rocks are representative for a large number of martian surface rocks.

\subsubsection{Site 1: "El Laco"}

Four large magnetite bodies with a total estimated ore resource of 500 million tons crop out around El Laco volcano in the central Andes (Fig. 2a; Alva-Valdivia et al., 2003; Naranjo et al., 2010). Together with the iron ore deposits of Kiruna (e.g. Jonnsson et al., 2013) they represent worldwide unique examples for very strong local magnetic anomalies, which may be comparable to that observed in some areas 
of the southern Noachian highlands of Mars (Connerney et al., 2005; Lillis et al., 2013).

The selected area with an extension of $0.2 \mathrm{~km} \times 0.4 \mathrm{~km}$ is situated at the northern margin of the El Laco Sur outcrop $\left(23^{\circ} 50^{\prime} 17^{\prime \prime} \mathrm{S} ; 67^{\circ} 29^{\prime} 27^{\prime \prime} \mathrm{W} ; 4720 \mathrm{~m}\right.$ elevation; Figs. 1, 2), at the transition between magnetite-bearing ores and Early Pleistocene andesitic lava flows, which are partly covered by pyroclastic deposits with up to $5 \mathrm{~m}$ thickness. The mapping area has not been modified by iron ore mining.

Sernageomin (Servicio Nacional de Geología y Minería of Chile; Naranjo et al., 2010) performed aeromagnetic surveys and constructed maps of the anomaly. They reflect a dipolar anomaly according to the isodynamic lines of the map with intensities of the order of $\pm 150 \mathrm{nT}$ (Alva-Valdivia et al., 2003). However, there is no information available concerning the tracks of these aeromagnetic surveys: spacing and altitudes above ground; therefore, the data are only considered for completeness. Furthermore, on-ground magnetic surveys have not been previously done.

Fission-track dating of apatite grown within the magnetites gave an age of $2.1 \pm 0.1 \mathrm{Ma}$ (Maksaev et al., 1988). A whole rock age of the andesite from the host rocks of Pico Laco is $2.0 \pm 0.3 \mathrm{Ma}$ (Gardeweg and Ramírez, 1985).

The origin of the magnetite bodies has been strongly debated. A combined magmatic and hydrothermal origin was proposed by Alva-Valdivia et al. (2003), Sillitoe and Burrows (2002), and Velasco and Tornos (2012). This is based on the fact that field and petrograhic evidences suggest that some magnetites have a primarily magmatic texture, whereas others show features that indicate a formation during a hydrothermal triggered re-emplacement of andesitic lava flows. Trace element compositions of the latter magnetite type are not compatible with a magmatic origin. For example, Dare et al. (2014) documented that these magnetites are characterized by high-Ni / Cr ratios, depleted in $\mathrm{Ti}, \mathrm{Al}, \mathrm{Cr}, \mathrm{Zr}$, Hf, and $\mathrm{Sc}$, and show an oscillating zoning of $\mathrm{Si}, \mathrm{Ca}, \mathrm{Mg}$, and rare earth elements. In contrast, oxygen isotope data $\left(\delta^{18} \mathrm{O}\right.$ of +2 to +4$)$ of many magnetites support a magmatic rather than hydrothermal origin (Jonnsson et al., 2013).

Microscopy studies under reflected light as well as temperature-dependent susceptibility measurements and isothermal remanent magnetization (IRM) acquisition show that low Ti-magnetite and/or maghemite are the magnetic carriers (Alva-Valdivia et al., 2003). Sometimes ilmenitehematite minerals appear in significant amounts. Grain sizes range from a few microns up to several millimetres. Hysteresis measurements of Alva-Valdivia et al. (2003) of seven ore samples from El Laco Sur point to pseudo-single-domain status and show a large range of Koenigsberger ratios $(Q$ ratios from 0.02 to $>1000$ ).

Palaeomagnetic data show distinct local declinations indicating a complex crystallization history, probably during different geomagnetic field orientations (Alva-Valdivia et al., 2003).

\subsubsection{Site 2: "Pali Aike"}

Lava sheets with volcanic spatter cones represent a common feature in many areas of the surface of Mars (Kereszturi and Németh, 2012; Robbins et al., 2013). On Earth such volcanic rocks often exhibit distinct magnetic anomalies (e.g. Bolós et al., 2012; Urrutia-Fucugauchi et al., 2012). However, only few examples have been mapped with high resolution (e.g. Cassidy and Locke, 2010).

Thus, an agglutinated spatter cone of $170 \mathrm{~m}$ diameter and surrounding Quaternary lava sheet of the Pali Aike volcanic field in southernmost Patagonia (Figs. 1, 3; Skewes and Stern, 1979) has been selected as potential martian analogue. The well-preserved morphology and stratigraphy indicates an age of approximately 1.0 Ma when considering the succession of various nearby volcanic formations for which ages of 0.16-1.5 Ma have been reported (Mejia et al., 2004). The investigated crater is partly filled by pyroclastic material, eolian sediments as well as blocks and detritus, which have been collapsed from the eastern inner crater wall.

The mapping site $\left(52^{\circ} 06^{\prime} 43^{\prime \prime} \mathrm{S} ; 69^{\circ} 42^{\prime} 28^{\prime \prime} \mathrm{W} ; 227 \mathrm{~m}\right.$ elevation) covers an area of $400 \mathrm{~m} \times 400 \mathrm{~m}$, including the crater and its surroundings (Fig. 3a).

\subsubsection{Site 3: "Monturaqui"}

Impact craters represent a very frequent feature on the Mars' surface (Lillis et al., 2013). Depending on, e.g., size, target rocks, impactite composition, and possible hydrothermal processes, they can be characterised by distinct and complex magnetic signatures (e.g. Osinski and Pierazzo, 2013). On Earth, large impact craters are strongly eroded. In addition, some of them are covered by vegetation or modified by anthropogenic influences. A Late Pleistocene simple type impact crater in the Atacama Desert of northern Chile was selected for this case study (Fig. 1). The crater was discovered in 1962 from aerial photographs and firstly described by Sánchez and Cassidy (1966). It is located at latitude $23^{\circ} 55^{\prime} 40^{\prime \prime} \mathrm{S}$ and longitude $68^{\circ} 15^{\prime} 42^{\prime \prime} \mathrm{W}$ at an elevation of $2984 \mathrm{~m}$ (Ugalde et al., 2007), has a diameter of $370 \mathrm{~m}$ and is $34 \mathrm{~m}$ deep (Fig. 4a, b, c), and was formed during the Quaternary $(660 \pm 90$ kyr BP; Ukstins Peate et al., 2010). Due to the arid climate, it remained morphologically well preserved. The crater has remarkable morphological similarities to the Bonneville impact crater on Mars, which was explored by the Spirit rover of NASA (Grant et al., 2004). Monturaqui target rocks include Jurassic granites cut by some mafic dykes. Both rock types are overlain by a several metre thick sheet of Pliocene ignimbrites. Tiny $\mathrm{Fe}-\mathrm{Ni}-\mathrm{Co}-\mathrm{P}$ spherules, all bound in impact glass, have been found within the ejecta blanket. They suggest an iron meteorite as impactor (Bunch and Cassidy, 1972; Kloberdanz, 2010). 


\subsubsection{Site 4: "Bahía Glacier"}

Plutonic rocks and layered intrusions form significant parts of the martian crust (e.g. Francis, 2011) and analogues on Earth (McEnroe et al., 2004, 2009). These rocks may have the capacity to store remanent magnetic signatures that can be used to distinguish between different magmatic rock types during future rover-based magnetic surveys. The Patagonian Batholith in the southernmost Andes provides a good example of continental crust formation on Earth and other planets (Kilian and Behrmann, 2003; Diaz-Michelena and Kilian, 2015). A small mapping area of $20 \mathrm{~m} \times 6 \mathrm{~m}\left(120 \mathrm{~m}^{2}\right)$ was defined on a Cretaceous granite (Fig. 5; Hervé et al., 2007), which is cross-cut by several mafic north-trending $\left(\sim 5^{\circ} \mathrm{N}\right)$ more or less parallel mafic dykes $\left(52^{\circ} 48^{\prime} 28^{\prime \prime} \mathrm{S}\right.$, $73^{\circ} 14^{\prime} 10^{\prime \prime} \mathrm{W}$; $11 \mathrm{~m}$ a.s.l.). This area was chosen because it is a good example of very low intensity magnetic contrast in a small extension, where transition between alternating mafic and felsic outcrops appears at a centimetre scale.

\subsection{Additional analyses}

The magnetic field surveys have been complemented with other rock analyses to improve the interpretation of the magnetic signatures of the surveys. Even though the detailed analysis is outside the scope of this work, the types of measurements are briefly described because they support partially some of the conclusions of the work.

Firstly, a macroscopic description of the rock types and mineral components has been done at each site. Representative rock samples were collected along the tracks for macroscopic investigation and future analyses in the laboratory. For instance, the samples from Pali Aike (site 2) and Bahía Glacier (site 4) have been analysed with polarization and refracted light microscopy of thin sections of the rocks. Texture and grain sizes of samples from El Laco (site 1) have also been investigated with a scanning electron microscope (Leo 435 VP, Geology Department, Trier University). The mineral composition of granites and amphibolitic dykes of the Bahía Glacier (site 4) have been analysed by an X-ray diffractometer (Siemens D500, Geology Department, Trier University).

Hysteresis properties of representative samples from Pali Aike (site 2) and Bahía Glacier (site 4) have been characterized magnetically at room temperature by means of a vibrating sample magnetometer at the Space Magnetism Laboratory of INTA, Spain. Magnetic susceptibilities have also been measured with a MS-2 susceptometer by Bartington along the transects at site 4 .

\section{Results}

The comparative performance and results of the magnetic surveys with the MOURA and G-858 magnetometers are described below. In all cases with identical single point mea- surements the correlation between the two instruments and the two sensors of the MOURA has been analysed. The number of differences among the distinct sites has made it possible to demonstrate the versatility of the MOURA. Thus, in each study case some of the individual capabilities of the instrument will be highlighted and discussed.

\subsection{Site 1: "El Laco"}

The surveys were performed with both instruments using continuous and discrete measurement modes. During the surveys the temperature was ranging from 5 to $27^{\circ} \mathrm{C}$. The transects and individual measuring points were georeferenced with the GPS. A MATLAB code was used to combine, interpolate, and merge the magnetic anomalies and tracks (Fig. 2). The vertical magnetic gradient has been measured at one point where magnetite-bearing ores crop out. Figure $2 b$ shows an exponential increase of the magnetic anomaly from $1.9 \mathrm{~m}$ altitude above the ground down to the rock surface (from +3000 to $+23000 \mathrm{nT}$ ). The gradient field calculated from the vector components of both vector sensors shows a strong negative vertical component $\left(m_{z}=-11.7 \mathrm{Am}^{-1}\right)$ for this point, which has been modelled by a local shallow superficial dipole with a volume of $0.1 \mathrm{~m} \times 0.1 \mathrm{~m} \times 0.4 \mathrm{~m}$, an inclination of $-62^{\circ}$ and a declination of $-67^{\circ}$.

The magnetite-bearing outcrops exhibit very high positive magnetic anomalies from 30000 to $>110000 \mathrm{nT}$, while surrounding andesitic lavas and pyroclastic material have much lower positive anomalies $(+100$ to $+2000 \mathrm{nT})$. The magnetic anomalies across outcrop transitions between andesites and magnetite-bearing ores have been measured with the MOURA in a discrete mode directly on the ground (Fig. 2c) and with a continuous mode (Fig. 2d). The differences in the intensity of andesite anomalies between these two measurements are related to the different and slightly variable distance between the hand-held sensor $(25-30 \mathrm{~cm})$ and the ground surface of single points $(0 \mathrm{~cm})$. The continuous measurements show a large variability of the magnetic anomalies along the ore-bearing outcrops related to either heterogeneous ore compositions or slight variations of the sensor distance from the surface.

During G-858 surveys, the magnetometer became often saturated when high local magnetic anomalies were reached $(>80000 \mathrm{nT})$. Local surveys with a higher spatial resolution in a continuous mode showed that this situation appeared very frequently and thus did not permit a complete highresolution survey with this instrument. The surveys with the MOURA were not affected by such saturation since this magnetometer has an extended range mode (auto) that doubles the nominal range to $\pm 130000 \mathrm{nT}$ per axis, and thus, allows for measurements up to higher field intensities, as it has been suggested partly for the martian surface. Despite this problem with the G-858 the scalar magnetic maps of both magnetometers are similar with a correlation $R^{2}>0.8$. (comparison in Fig. 2e and f). Of relevant importance is that the MOURA 


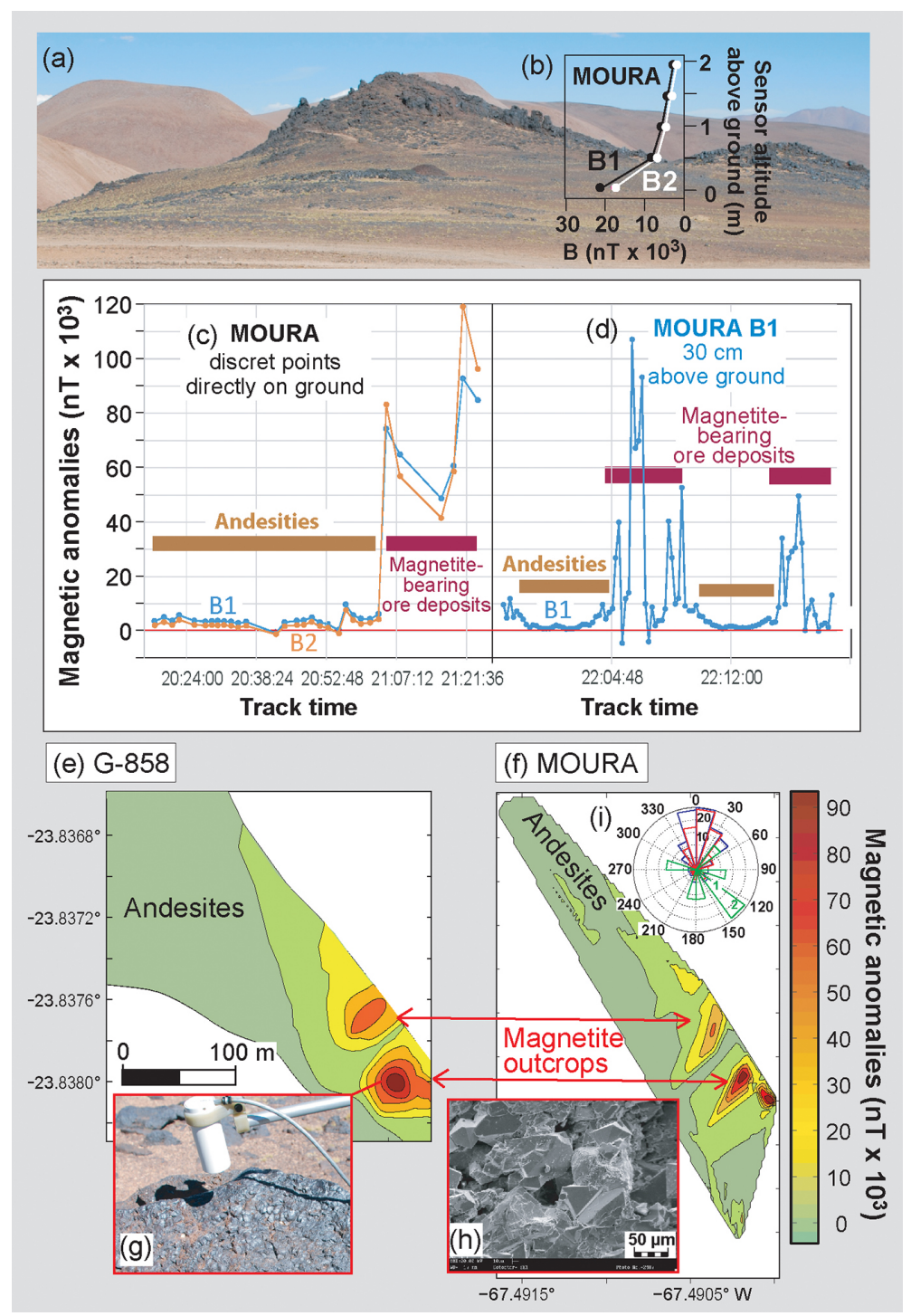

Figure 2. Magnetic and geological features of El Laco Sur. (a) A $150 \mathrm{~m}$ wide outcrop of magnetite-bearing ores. (b) the MOURA vector measurements at different distance from the ground. (c) the MOURA track with discrete measuring points across the transition between andesite and magnetite-bearing ore outcrops. (d) The MOURA track with the sensor B1 in a continuous mode across different patches of andesites and outcrops of magnetite-bearing ores. (e) Interpolated map calculated from survey tracks with G-858 magnetometer. (f) Interpolated map based on the MOURA mapping. (g) G-858 sensor head on a magnetite-bearing rock surface. (h) Secondary electron image of the magnetite-bearing rock surface. (i) Comparison of declination frequencies calculated from the MOURA vector sensors (B1 in blue and B2 in red) along a $950 \mathrm{~m}$ long track line including 125 data points. Green orientations indicate palaeo-declinations determined by Alva-Valdivia et al. (2003).

magnetometer allows for the identification of the component that saturates.

Since the MOURA magnetometer provides vector magnetic data, it is possible to determine the orientation of the field in the area. This is shown in the rosette of Fig. 2i together with the palaeo-declinations of other rock samples from El Laco Sur determined by Alva Valdivia et al. (2003).

\subsection{Site 2: "Pali Aike"}

A dense grid was performed over the depicted surface with G-858 magnetometer (Fig. 3a). In this case, the MOURA measurements have been performed with the discrete mode (Fig. 3b) to obtain well-referenced vector data. During the survey, the temperature was oscillating between 7 and $15^{\circ} \mathrm{C}$.

Figure $3 \mathrm{~b}$ compares an interpolated magnetic anomaly map measured with G-858 with discrete points from the MOURA that are illustrated with a colour code. Both data 

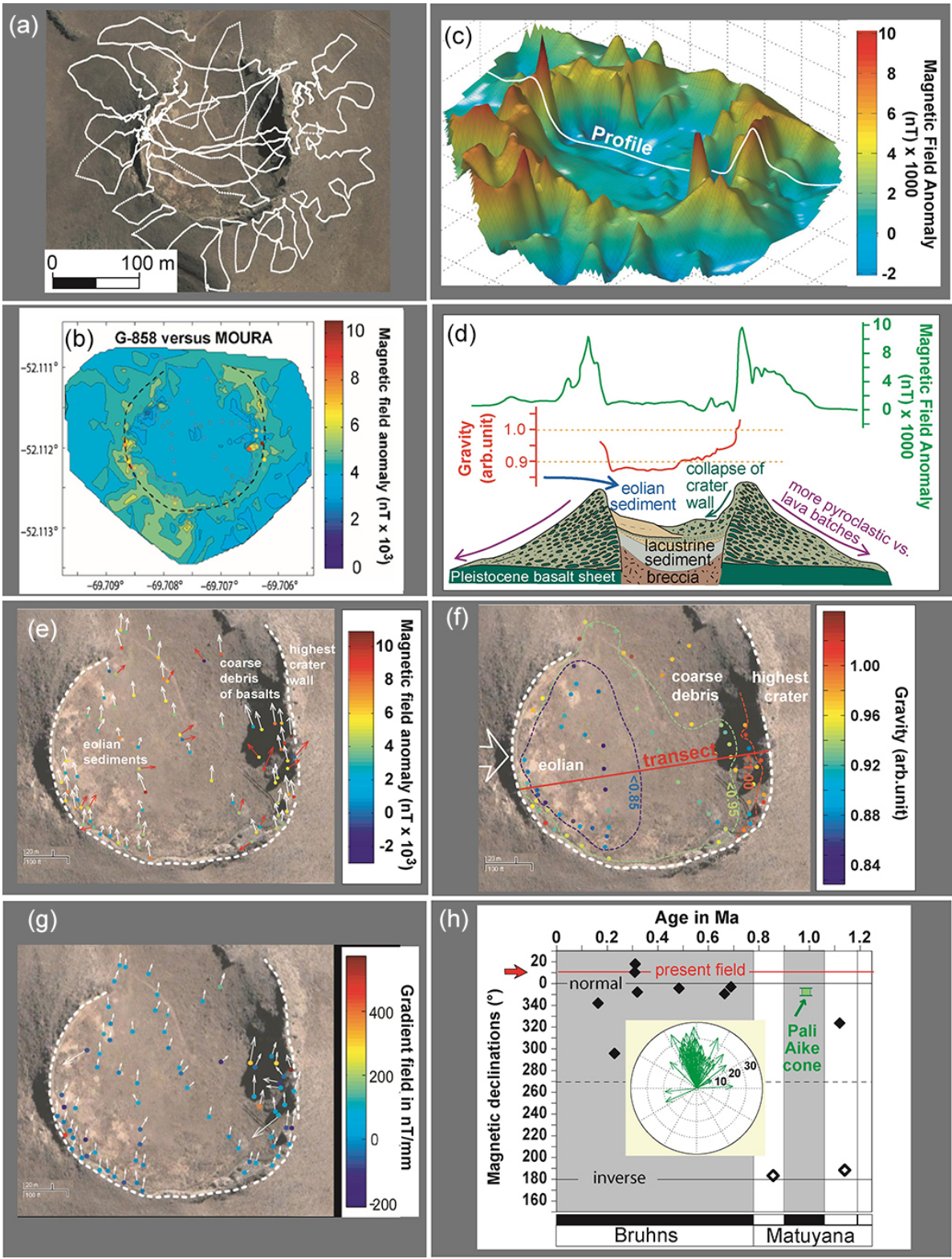

Figure 3. Magnetic and geological aspects of a Pali Aike crater and its surroundings. (a) Survey grid with G-858. (b) Comparison of the interpolated magnetic anomaly map of G-858 and discrete measurements of the MOURA shown in a comparable colour code. (c) 3-D view of interpolated magnetic anomalies with the position of the transect shown in (d). (d) East-west transect across the crater and its geological structure. Magnetic field anomalies are indicated in green and gravity values in red. (e) Magnetic anomalies of the MOURA and its declination. Red arrows indicate declinations of removed blocks and white arrows that of consolidated rocks. (f) Gravity measurement points in the crater. A white arrow indicates the direction of typical westerly wind and related eolian deposits in the crater. $(\mathbf{g}) \mathrm{B}_{z x}, \mathrm{~B}_{z y}$, and $\mathrm{B}_{z z}$ components of the gradient field in $\mathrm{nT} \mathrm{mm}^{-1}$. (h) Quaternary palaeomagnetic anomalies. Single diamond data points indicate ages and palaeo-orientations of different old volcanic rocks of Pali Aike determined by Mejia et al. (2004) and a rosette indicates declinations measured with the MOURA.

sets match very well $\left(R^{2}>0.82\right)$. A 3-D view of the interpolated magnetic anomalies mapped with G-858 is shown in Fig. 3c. It documents the very high positive anomalies of the crater rim (up to $+12000 \mathrm{nT}$ ). A west-east transect of the crater and its surroundings, and its geological features shows two pronounced positive magnetic anomalies centred at both sides of the crater rim where the agglutinated spatter have been mainly deposited as pillow-like blocks of metre size (Fig. 3d).

Vector information obtained with the MOURA magnetometer at the individual points along the crater rim and crater infill is illustrated in Fig. 3e. In general the predom- 
inant declination in all the measurements taken on consolidated lava blocks and the sedimentary infill is around $355^{\circ} \mathrm{N}$ (white arrows in Fig. 3e). However, anomalous deviations have been detected in the eastern and southern part of the crater (red arrows in Fig. 3e), on single basaltic lava blocks, which have moved into the crater during a post-eruptive collapse of the inner crater wall.

The MOURA has two magnetometers with a small vertical distance of $10 \mathrm{~mm}$ between them. They also can be used to measure some of the components of the gradient of the field. Figure $3 \mathrm{~g}$ shows the derivatives with respect to $z$ of the components $\mathrm{B}_{x}, \mathrm{~B}_{y}$, and $\mathrm{B}_{z}$ of the field. In good agreement with the previous conclusion, the gradient seems to have a homogeneous direction all over the crater with the exception of measurements on single lava blocks that have been removed and re-orientated during the collapse of the wall.

For, all these data the tilt angle of the MOURA has been taken into account apart from the deviation with respect to the north taken with the GPS. This has been possible due to the fact that the MOURA has a tilt angle sensor to measure the deviation from the horizontal. This sensor has been used in this example to derive a gravity contrast along the transect within the crater and along its rim, which is illustrated in Fig. 3f. Highest values occur along the eastern and western crater rim whereas lowest values are measured at the western eolian sedimentary crater infill. This relationship is shown in the W-E transect of Fig. 3d.

\subsection{Site 3: "Monturaqui"}

In this example we performed a dense grid of the centre of the crater as well as the northeastern, eastern, and southern part of the crater rim. An interpolated map shows very slight magnetic anomalies $(<50 \mathrm{nT})$ within the crater (Fig. $4 \mathrm{~b})$ whereas more pronounced local negative and positive anomalies from -400 to $>+600 \mathrm{nT}$ occur within several meters along the crater rim, indicating the existence of metre-sized dipoles. The anomalies are not related to outcrops of exposed granitoids and ignimbrites (Fig. 4c).

A higher-resolution mapping was performed at a local area of around $10 \mathrm{~m} \times 20 \mathrm{~m}$ at the north-eastern crater rim with both magnetometers in a continuous mode with G-858 and by discrete points with the MOURA. Both magnetometers show relatively high positive and negative anomalies ranging from -3500 up to $>+6000 \mathrm{nT}$ (Fig. 4d). This local field of anomalies indicate the existence of not exposed but nearsurface metre-sized dipoles. The anomalies measured with both magnetometers are compared in the $X-Y$ plot of Fig. $4 \mathrm{e}$ and indicate a correlation of $R^{2}$ of 0.81 .

The local mapping area at the north-eastern crater rim is characterised by pronounced local topography changes in the range of $\pm 5 \mathrm{~m}$ of elevation. Figure $4 \mathrm{f}$ illustrates that more pronounced negative anomalies occur at topographic lows. This relationship between lower topography points and higher positive anomalies (and vice versa) was also measured with the B1 and B2 sensors of the MOURA and is shown in Fig. 4g. This figure also documents the good correlation between both the MOURA sensors, B1 showing on average +1500 to $+2000 \mathrm{nT}$ higher values than $\mathrm{B} 2$, which is related to the fact that $\mathrm{B} 1$ is $10 \mathrm{~mm}$ nearer to the ground surface.

\subsection{Site 4: "Bahía Glacier"}

A $20 \mathrm{~m} \times 20 \mathrm{~m}$ area was mapped with G-858 and the MOURA magnetometers along seven high-resolution tracks perpendicular to the dykes (Fig. 5b, d) using both continuous and discrete modes. The spacing between the lines is approximately $80 \mathrm{~cm}$ and the distance between individual measurement points along the lines range from 5 to $10 \mathrm{~cm}$. All the lines show similar patterns, which allow for performing an interpolated map of the area: Fig. $5 \mathrm{c}$ and d show that the dykes clearly contrast with the granites by slight positive anomalies.

Figure 5e shows one of the high-resolution transects where the magnetic signatures have been measured with both magnetometers and a M2 Bartington device for susceptibilities. The dykes exhibit very clear but weak positive anomalies with respect to the granite in the range from +20 to $+80 \mathrm{nT}$. Both magnetometers show similar patterns $\left(\mathrm{R}^{2}>0.8\right)$. Overall slightly higher values (around $30 \mathrm{nT}$ ) of the MOURA data are attributed to the fact that they have been performed directly on the rock surface, whereas those of G-858 magnetometer are measured at a certain distance to the surface (25$30 \mathrm{~cm}$ ). The susceptibility transect shows a very sharp transition at the interfaces between the granite and dykes, the latter having around $70 \times 10^{-6} \mathrm{SI}$ higher values on average. However, the pattern of the magnetic anomalies are laterally displaced with respect to the surface transitions (Fig. 6). This reflects the eastward tilt of the dykes, which have dipping angles of $50-80^{\circ}$ and indicates that the uppermost $2-3 \mathrm{~m}$ of the mafic dykes are also integrated within the anomalies measured with both magnetometers while the susceptibility shows only the information of the first centimetres below the surface.

Detailed petrographic studies including electron microprobe and X-ray diffraction (XRD) analysis show that both granites and amphibolitic dykes do not contain magnetite, but instead include ferromagnetic monoclinic $\mathrm{C} 4$ pyrrhotite as magnetic carrier. Areal microscopic mapping of pyrrhotite in thin sections of the different dykes and the granite and XRD analyses of the different rocks indicate a content of $1-4$ vol $\%$ pyrrhotite with grain sizes ranging from $<5$ to $150 \mu \mathrm{m}$. There is a good correlation between the pyrrhotite contents of the different dykes and the amount of the positive anomalies (Fig. 5e). 

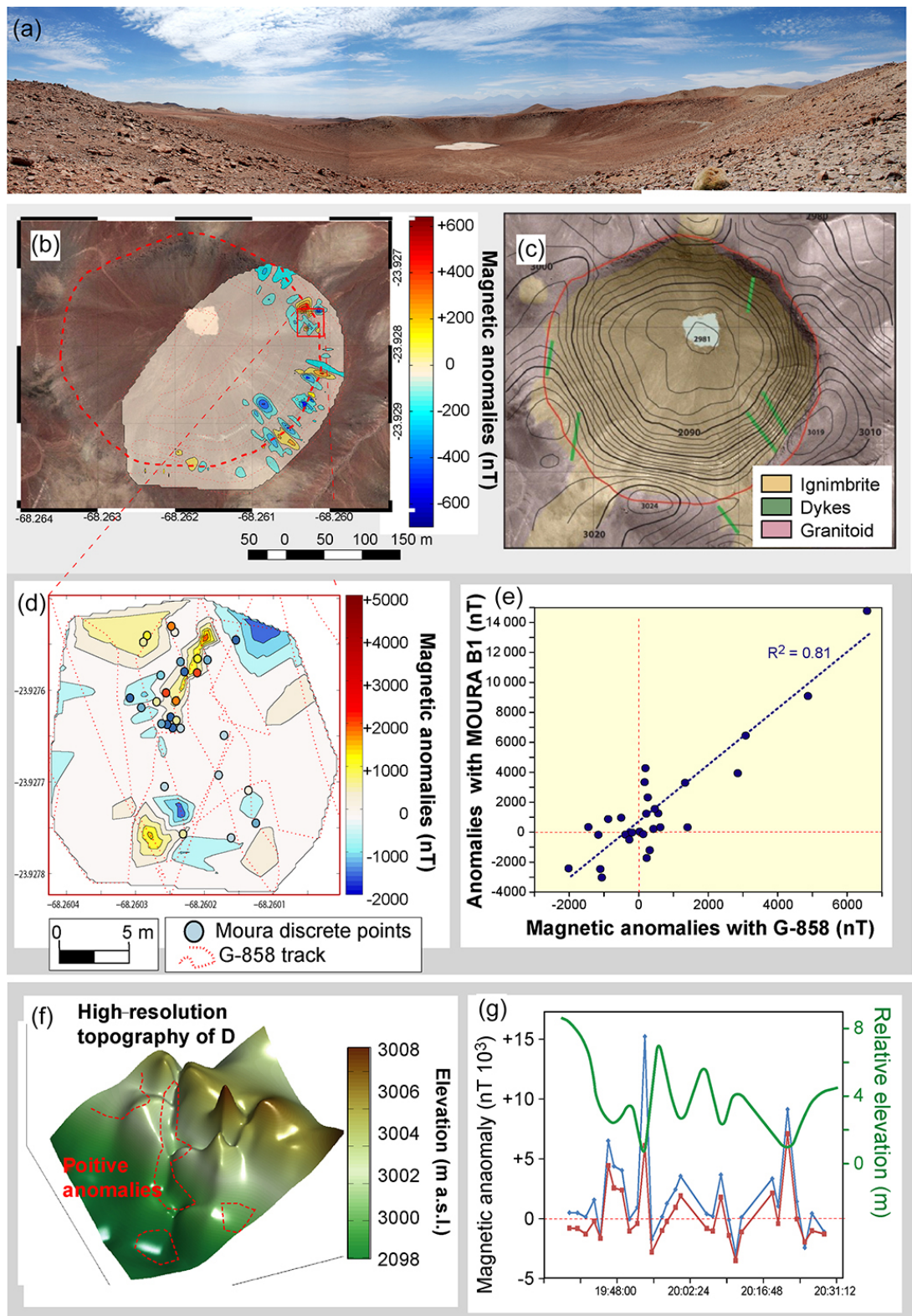

Figure 4. Magnetic and geological features of Monturaqui impact crater. (a) photo of the crater looking towards the north. (b) Track (red stippled line) and interpolated mapping grid of G-858. (c) Topography and exposed geological units. (d) Detailed mapping area at the northeastern crater rim with discrete magnetic data points of the MOURA on an interpolated magnetic map of G-858. (d) $X-Y$ comparison of the MOURA sensor B1 with G-858 data. (f) Topography of the local mapping area (shown in d) and areas with stronger positive anomalies at topographic lows marked in red. (g) Comparison of the MOURA B1 and B2 data and their local elevation.

\section{Discussion}

The results of the different ground magnetic surveys of both magnetometers are discussed with respect to the appropriateness of the different instruments and the relationship to mineralogical and magnetic properties of the exposed rocks. In particular the potential of high-resolution detection of weak magnetic contrast between different surface rock types is considered.

\subsection{Instrument performance}

Final processed data from both instruments show a very good correlation in intensity of magnetic anomalies (in all cases $R^{2}>0.8$ ) for the overall measurement range between -2000 and $100000 \mathrm{nT}$ (Figs. 2e, f, 3c, 4e, 5e).

The stability of both instruments has been appropriate for the different surveys. G-858 MagMapper shows a better thermal stability, which can be observed during faster tempera- 

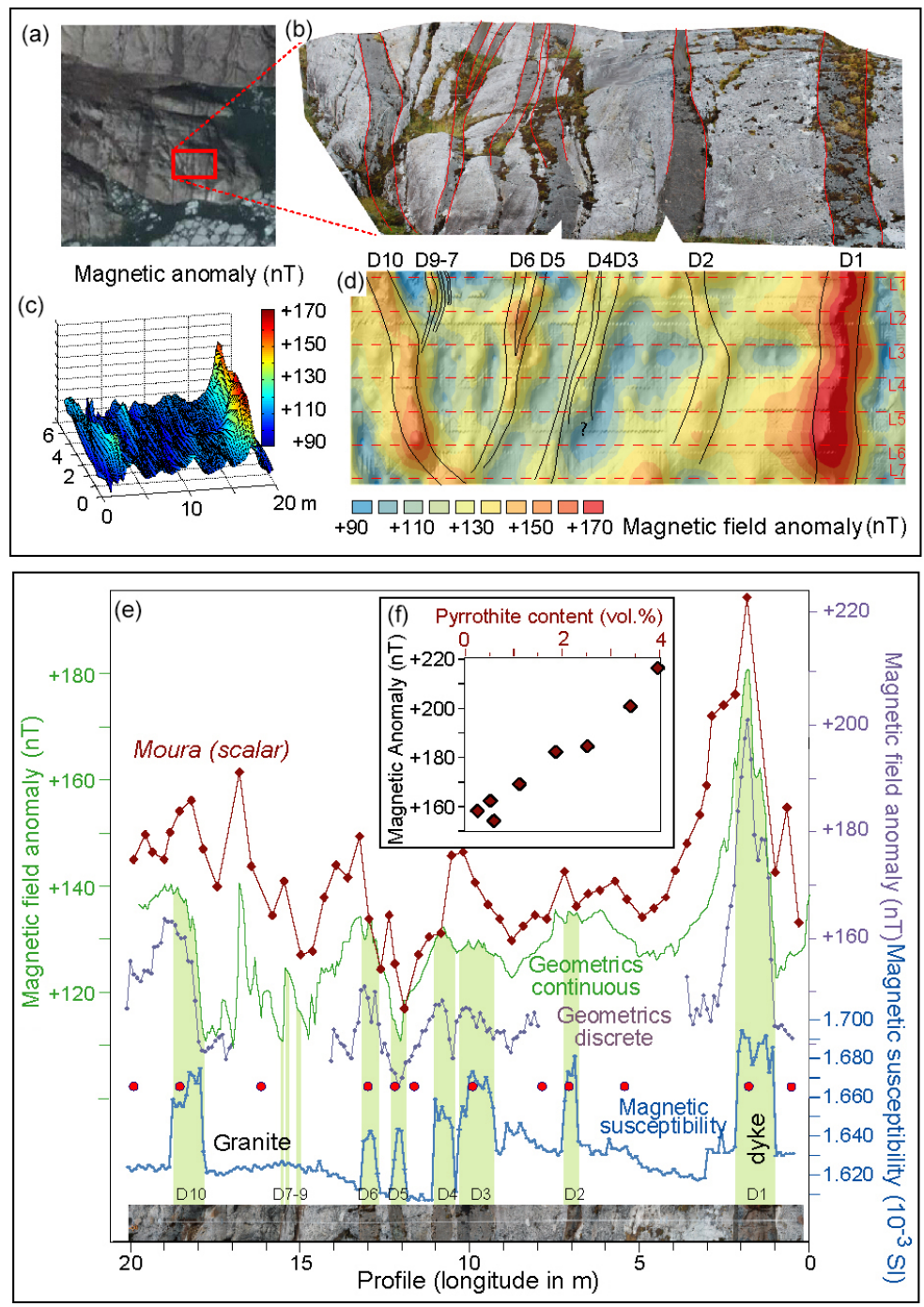

Figure 5. The Bahía Glacier mapping area with mafic dykes in a granite: (a) Google Earth view of the Patagonian batholith with the local mapping area marked in red. (b) Local mapping area with dark dykes in a granite. (c) Interpolated 3-D map of G-858 mapping. (d) Magnetic anomalies of the mapping area with measuring lines L1-L7. (e) Comparison of the intensity of the magnetic anomalies measured by both magnetometers (Geometrics 858 in discrete and continuous mode, and the MOURA) and susceptibilities, all of them measured in a transect perpendicular to the dykes D1-D10 (marked in green). Red dots indicate sample locations along the transect. (f) Pyrrothite content versus intensity of the magnetic anomaly.

ture variations during dawn and dusk, when the transducer may experiment thermal variations up to $0.1^{\circ} \mathrm{Cmin}^{-1}$. The simultaneous measurement of the temperature and the magnetic field during the prospections diminishes this problem, which can be neglected in areas with magnetic anomalies $>100 \mathrm{nT}$, but the error can be significant $(1 \%)$ in low contrast anomalies (in the range of $1 \mathrm{nT}$ ), also due to the resolution of the MOURA instrument. Other ways to compensate the temperature effects could improve these errors (DíazMichelena et al., 2015b). For static measurements the simultaneous temperature measurement corrects very well the magnetic field data (Díaz-Michelena et al., 2015a).
Regarding the dynamic range, both magnetometers have also casted appropriate results in most of the cases. The limitation in this feature affects in a different way the response of both instruments. G-858 is influenced in the measured modulus of the field, while the MOURA is affected separately in every axis. Apart from the extension of the range in modulus, this is an advantage since it could provide useful data in two directions in spite of saturation in the other axis. For example, at site 1, the huge intensity of the anomalies makes it impossible to map them with G-858, while the MOURA can measure them in the auto mode, when the maximum offset is applied. 


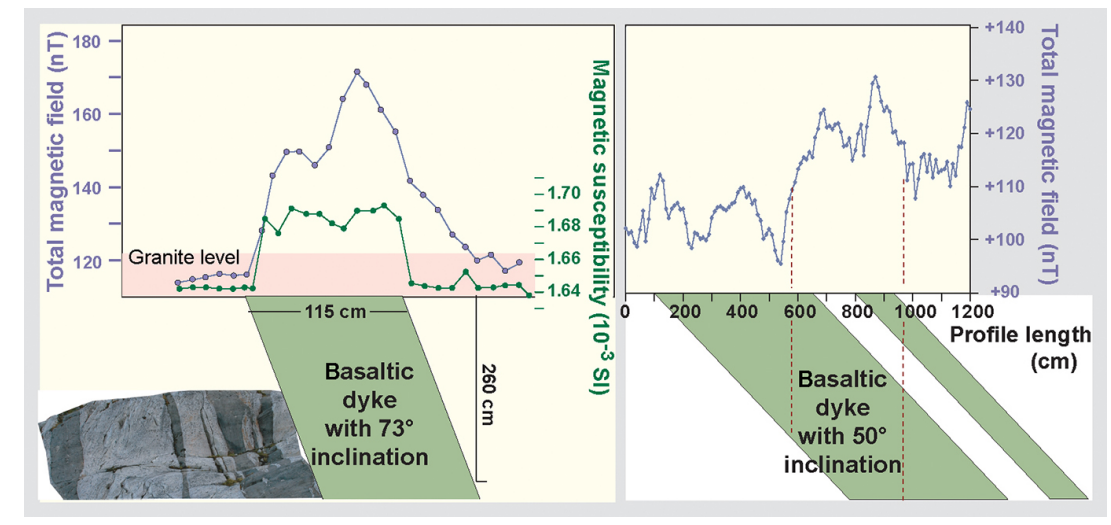

Figure 6. Magnetic effects of inclined dykes in perpendicular transects. (Left) Asymmetry of the D 1 dykes, which is caused by its $70^{\circ}$ inclination capturing a local signal up to $260 \mathrm{~cm}$ depth. (Right) A $500 \mathrm{~cm}$ wide dyke with an inclination of up to $50^{\circ}$ integrating deeper signatures up to more than $500 \mathrm{~m}$ depth.

At the El Laco site, the MOURA surveys were performed with discrete and continuous modes. The continuous mode enabled a higher resolution and an easier performance but it may include a shifting by slight variations of the distance between sensor and the ground. The extreme high gradient at this site causes a pronounced fluctuation of around $>5000 \mathrm{nT}$ when altitude of the sensor changes from 25 to $30 \mathrm{~cm}$. This can be avoided by discrete measurements directly on the ground, which also enable a better orientation control of the vector sensor. In the case of highly positive anomalies and in combination with high $Q$ ratios (remanent versus induced magnetic signatures) of the surface rocks, the vector measurements may also have the capability for palaeomagnetic implications, which is extremely important for planetary exploration.

Surface rock alteration processes, which modify the magnetic signatures, have influence on limited areas. In particular, the related mineral transformations processes are a direct consequence of the contact of the rocks with the hydrosphere and atmosphere, and their influence depth is limited to several tens of metres. This fact together with the exhumation processes often offers the possibility to correlate the measured direction of the magnetization with the coetaneous palaeomagnetic field. In the case of Mars, where the main source of field is the remanent magnetization, oriented measurements does not only contain information on the carriers and the possible alteration effects suffered by them, but also record the palaeomagnetic field orientation. This possible tool has been applied to remanence dominated sites, which is further discussed in Sect. 4.2.

The sensor head orientation is also a matter for discussion. Despite the good signal-to-noise ratio presented by the scalar magnetometer, it is affected by the relative orientation of the head and the magnetic field vector. This is highly improved in a three-axes magnetometer like the MOURA.

Another consideration is the gradient immunity and capability to derive a gradient of the field of the instruments. On the one hand, the MOURA instrument presents a better gradient immunity, which makes it very suitable to map areas with high frequency patching of the signatures. For example, it is very appropriate to perform decimetre-scale resolution mappings like in the cases of El Laco, Monturaqui, and Bahía Glacier. G-858 presents troubles with moderate gradients $\left(>20000 \mathrm{nT} \mathrm{m}^{-1}\right)$.

On the other hand, the inclusion of a second head (and therefore having two three-axes magnetometers) in the MOURA instrument offers the capability to better understand the characteristics and depths of the sources. This cannot be applied to deep and extended magnetic sources, because the distance between the two magnetometers is very small $(10 \mathrm{~mm})$ but it is useful to analyse near-surface heterogeneities and will be discussed in Sect. 4.2.

\subsection{Capacity for high-resolution mapping with tracing of mineralogical and geological characteristics}

High-resolution ground surveys may indicate compositional variations in soils and/or uppermost crustal rocks, depending on the magnetic contrast between different exposed rocks and the intensity of active magnetic field (Gobashy and AlGarni, 2008; Hinze et al., 2013). Despite the fact that it is not the primary goal of the MOURA instrument, which is part of the instruments suite of a lander, due to its potential in future exploration missions, the capacity of the commercial G-858 and the MOURA magnetometer for extraterrestrial high-resolution mapping is discussed in the following for the different investigated sites.

\subsubsection{El Laco}

At this site the intensities in the magnetic anomalies range from 0 to $+110000 \mathrm{nT}$ (Fig. 2c, d, e, f), which is unique compared to other magnetic mapping results on Earth (e.g. Hinze et al., 2013). The magnetic contrast at the surface tran- 
sition between andesitic rocks and magnetite-bearing ores is very sharp and extremely high. A change from +1200 to $+80000 \mathrm{nT}$ appears in less than a metre distance. In general, the MOURA data show a better definition of the surface rock transitions and local variabilities in the areas with outcrops of magnetite-bearing ores compared to G-858. Furthermore, G-858 could not register some of the anomalies because its response was occasionally saturated (110000 nT) (Fig. 2d). Some variations in areas with exposed ores (of the order of $\pm 5000 \mathrm{nT}$ ) could have been caused by slight changes in the sensor distance from the ground during a continuous measuring mode (see Sect. 3.1), the major variations are probably related to the heterogeneous composition and locally distinct magnetic behaviour of the magnetite-bearing ores. The texture of magnetites in the ores indicates in part not only a primarily volcanic origin, but also frequent recrystallization during later hydrothermal processes can be observed. It is likely that the hydrothermal crystallization took place over a longer period of the Early Quaternary, which may have also included magnetic reversals (e.g. Alva-Valdivia et al., 2003; Naranjo et al., 2010). Our field observations and laboratory analyses of collected samples indicate a large scatter in the grain sizes, the porosity content as well as the relative amount of additional apatite (non-magnetic) and pyroxene in these rocks. These features might explain the observed variations. Other variables reported by Alva-Valdivia et al. (2003) include hysteresis parameters and highly variable $Q$ ratios (from 0.01 to $>5000$ ) indicating a wide range of individual properties of the magnetic carriers, compatible with pseudosingle-domain up to multi-domain status. Therefore, we attribute the observed huge variability in magnetic anomalies to local variabilities in the behaviour and magnetic properties of magnetites in near-surface rocks.

In areas where andesitic lavas are exposed, field surveys show only low fluctuations of the positive anomalies (Fig. 2c, d). This let us to hypothesize that there are no underlying local ore bodies and the lava flows have relatively homogenous compositions.

Measurements with the MOURA vector magnetometer show a clear northward declination between 350 and $10^{\circ} \mathrm{N}$ (Fig. 2i). This value is similar to the present declination of the IRGF at this site $\left(3^{\circ} \mathrm{N}\right)$ and can be explained by a very strong induced magnetization consistent with the very high susceptibilities, but relatively low $Q$ ratios (0.01) measured in six of seven samples from El Laco Sur by Alva-Valdivia et al. (2003).

\subsubsection{Pali Aike}

Magnetic surveys have been performed at some volcanoes worldwide with different spatial resolution, e.g. from Australia (Blaikie et al., 2012), New Zealand (Cassidy and Locke, 2010), and Italy (Okuma et al., 2009). In general these case studies show more and less positive magnetic anomalies (up to a few thousand nT) depending on the composition of the volcanic rocks, its cooling history, and the single versus multi-domain status of their magnetites (Clark, 1997). Our example of a small crater $(170 \mathrm{~m}$ diameter) and its surroundings at the Pali Aike volcanic field was performed with both magnetometers and with a higher spatial resolution than the previous studies. The transect across the Pali Aike crater shown in Fig. 3c and d has a spatial resolution of $30-50 \mathrm{~cm}$ in-between individual measuring points and thus provides a very good differentiation of different kinds of exposed rocks within the uppermost $1-2 \mathrm{~m}$.

Despite the relatively high intensity of the IGRF at Pali Aike $(+31000$ nT; Fig. 1) the transect across the crater is characterised by very high positive magnetic anomalies of up to $+12000 \mathrm{nT}$. These anomalies are more pronounced along the crater rim where metre-sized melt spatters have been deposited and cooled down (Fig. 3d). The very strong magnetic signature can be explained by the fact that these lavas contain very frequent tiny magnetite crystals with single domain characteristics in their glassy matrix. The positive anomalies become much lower towards the crater infill and the outer slopes of the crater. An increasing amount of pyroclastic deposits with reorientations during the deposition processes on the steeper slopes of the crater could have reduced the integrated magnetic anomaly of these components. The relatively low local anomalies measured within the crater can be also explained by such multiple re-orientations of magnetic carriers during local redistribution processes including fluvial and eolian activities.

Figure $3 \mathrm{e}$ shows arrows for the declination calculated from the vector data of the MOURA. The values of all measurements on consolidated lava blocks (white arrows in Fig. 3e) range from 352 to $360^{\circ} \mathrm{N}$. These orientations may reflect either the induced present magnetic field or palaeofield directions, or a combination of both, depending on their remanence and related $Q$ ratios, which reflect often the single versus multi-domain status of the basalts. Hysteresis measurements of 25 basaltic lava samples from our mapping area indicate relatively high $Q$ ratios of 50 to $>500$ suggesting a strong remanence. Comparable basaltic rocks from other sites worldwide are also characterized by a very strong remanence and a predominant single domain status (Day et al., 1997; Dos Santos et al., 2015; Dunlop, 2002; Zhao et al., 2006). Our measurements, which have been performed directly on detached lava and scoria blocks, clearly collapsed from the inner crater wall, show multiple orientations. They are indicated by red arrows in Fig. 3e and include easterly and westerly declinations.

The present field, which has a declination of $12^{\circ} \mathrm{N}$ at Pali Aike, the MOURA field vectors as well as several palaeodeclinations from different old Pleistocene lavas of Pali Aike (including magnetic reversals; Mejía et al., 2004) have been compiled in Fig. 3h. The estimated age of the investigated cone is approx. 1.0 Ma, which suggests a normal global field for that time. The MOURA declinations, ranging from 352 to $360^{\circ} \mathrm{N}$, are in a very good agreement with such a normal 
declination as well as other normal declination constrained for other lavas from the Bruhns magnetic period (Mejía et al., 2004) rather than the present field declinations, which contrast by $+15^{\circ}$. This result indicates that the MOURA magnetometer could provide palaeo-declinations when rocks have a very high remanence (high $Q$ ratios).

\subsubsection{Monturaqui impact crater}

Planetary impact craters can be characterised by a variety of magnetic anomalies, which are related in particular to distinct magnetic carriers of the target rocks (e.g. mafic versus felsic or sedimentary) and the sedimentary crater infill as well as the compositions of the impactor, impact-induced melt/glass and/or impact-related hydrothermal mineralization and/or demagnetization (e.g. L'Heureux et al., 2008; Langlais and Thébault, 2011; Osinski and Pierazzo, 2013; Pilkington and Grieve, 1992; Prezzi et al., 2012).

At the relatively small Monturaqui crater, a coarse grid of magnetic mapping with spacings of approximately $70 \mathrm{~m}$ inbetween single measuring points have been previously performed with a caesium magnetometer in the crater and its surroundings by Ugalde et al. (2007). The published interpolated map shows only very low magnetic anomalies in the range of less than $\pm 200 \mathrm{nT}$ with slightly higher values in the southern and eastern sector of the crater rim. Our grid was measured with a continuous mode of the G-858 and provides a much higher resolution for the central part of the crater as well as its northern, eastern, and southern rim and slopes (Fig. 4b). Our data show similar low magnetic anomalies of $\pm 50 \mathrm{nT}$ for the crater floor as measured by Ugalde et al. (2007), whereas the eastern and north-eastern crater rim is characterised by much stronger local anomalies from -500 to $>+600 \mathrm{nT}$. The transitions of the outcrops of granitic and ignimbritic target rocks shown in Fig. 4c cannot be depicted by the distinct anomalies, while two northwest to southeasttrending dykes seem to be responsible for some anomalies at the eastern crater rim (Fig. 4b). In general, the crater rim is characterised by a patchwork of pronounced local positive and negative anomalies, which can be caused by small-scale near-surface dipoles that are probably not exposed. Nonexposed fragments of the impactor, for which a diameter of $\sim 15 \mathrm{~m}$ has been modelled (Echaurren et al., 2005), represent a potential source for these magnetic anomalies. $\mathrm{Fe}-\mathrm{Ni}$ spherules, which have been found in impact melt/glass fragments along the eastern and western crater rim has been classified as a group I coarse octahedrite (Bunch and Cassidy, 1972; Buchwald, 1975) and contain schreibersite, cohenite, fossil taenite, and kamacite as major components as well as some troilite. Laboratory analyses of these components show both high remanent magnetization as well as very high susceptibility (Ugalde et al., 2007; Ukstins Peate et al., 2010).

The very pronounced negative to positive anomalies from -2000 to $+5000 \mathrm{nT}$, which have been mapped in a local area of $50-100 \mathrm{~m}$ extension at the northeastern crater rim
(Fig. 4d) also require near-surface rocks with strong dipoles. Non-exposed metre-sized fragments of the iron-bearing impactor represent the most likely explanation. In this local area topographic highs are formed by ignimbrite blocks of low-magnetic signature, which have been ejected from the crater and deposited on the rim during the impact event. Topographic highs formed by these blocks cause a higher distance of the magnetic sensor with respect to the probably underlying fragments of the impactor, while measurements in topographic lows show much higher positive anomalies (Fig. 4f, g).

\subsubsection{Bahía Glacier}

Mafic dykes within felsic to intermediate crustal rocks often produce pronounced local positive magnetic anomalies since they include frequent tiny magnetites (e.g. Hinze et al., 2013). However, in our case study the petrographical investigations indicate that the investigated dykes have not preserved their original magmatic mineral textures and the mineral assemblage point to an emplacement and later equilibration of the dykes under upper greenschist to amphibolite facies conditions (Bucher and Grapes, 2011; Philpotts and Ague, 2009). Granites and dykes do not contain magnetite, but both contain monoclinic pyrrothite as magnetic carrier (Dekkers, 1988, 1989; Clark, 1984). This mineral appears disseminated and along veins and has been formed during hydrothermal mineralization together with $\mathrm{Cu}$ and $\mathrm{Au}$ enrichments during the exhumation (Díaz-Michelena and Kilian 2015; Nelson, 1996; Schalamuk et al., 1997).

Despite the lower potential of pyrrhotite to produced magnetic anomalies both magnetometers (MOURA and G-858) clearly show high resolution and slightly positive magnetic anomalies $(+30$ to $+80 \mathrm{nT})$ as well as higher susceptibilities of the dykes compared to the granites (Fig. 5e). The surface transitions between dykes and granites are characterised by very sharp anomalies within a decimetre scale. The amount of pyrrothite (1-4 vol \%), which has been quantified in samples of the granite and seven dykes, shows a very good correlation with the intensity of the positive anomaly (from +160 to $+220 \mathrm{nT}$; Fig. 5f). This result confirms the potential of both magnetometers to explore local mineral enrichments, which are often produced by hydrothermal processes associated with gold and copper enrichments (Direen et al., 2008).

Hinze et al. (2013) show examples of mafic dykes in felsic rocks where different dyke geometries cause distinct shapes of local magnetic anomalies across dykes. For the investigated Bahía Glacier site, Fig. 6 illustrates asymmetric behaviour of the magnetic anomalies along lines, which have been measured across dykes that dip between 50 and $80^{\circ}$. All anomalies are slightly displaced towards the shallower dipping site of the dykes indicating an integration of the magnetic signature of the uppermost $2-3 \mathrm{~m}$ of not exposed dykes. This fact together with the difference in contrast obtained with the magnetometers and the susceptome- 
ter (Fig. 5) points out that the magnetic field measurements average large volume sources and can lead to wrong conclusions if used as a quantitative mineralogical marker. These results indicate that multi-head (magnetometer and susceptometer) instruments would provide much better results for this purpose.

\section{Conclusions}

Several sites with a huge variability in magnetic anomalies have been analysed. As a first conclusion it can be said that the surface measurement of the sourced field often gives direct information on the composition, petrogenesis, and alteration processes of the surface rocks.

For the study, two different magnetometers have been used. On the one hand, the MOURA vector magnetometer and gradiometer $(<200 \mathrm{~g}$ : $72 \mathrm{~g}$ instrument + batteries and control PC), developed for Mars surface measurements, as the demonstration of the technology for planetary surveys, and on the other hand, a commercial caesium G-858 magnetometer $(8-9 \mathrm{~kg})$, also used as a reference. The studied areas are considered Mars analogues and they are representative of the intensity range of the expected anomalies on the red planet crust.

According to the comparison with the reference instrument, it has been demonstrated that the MOURA magnetometer is not only appropriate for the static measurement of the absolute value of the magnetic field and its temporal variations, but also suitable for the prospection measurements in the range of sourced fields from $<15000$ to $>120000 \mathrm{nT}$ and to reproduce the magnetic contrast of the terrains. Furthermore, the MOURA offers vector data of the field and components of the gradient with a significantly lower mass.

The particular conclusions for the four case studies are the following:

1. El Laco magnetite-bearing ore deposits in the northern Andes of Chile represents a worldwide unique example with extremely high on-ground anomalies ranging from +30000 to +110000 nT, which may be comparable to highly magnetic rocks of the Noachian martian crust.

In this case the MOURA enabled better results than G-858 due its larger range of operation (130000 nT along each axis). The declinations measured also by the MOURA vectors represent the active global field due to induced-dominated magnetic rock properties with very low $Q$ ratios.

2. A crater in the Pali Aike volcanic field, in southern Chile, shows very high positive magnetic anomalies (up to $12000 \mathrm{nT}$ ) in its crater rim caused by frequent tiny and single domain magnetite crystals in the matrix of basaltic lava spatters.

Since these rocks, like that of many other comparable volcanic rocks on Earth and other planets, have high
Koenigsberger ratios $(Q)$ and thus are dominated by their remanence, the MOURA vector data have been used to determine the palaeomagnetic orientation during the crater formation around $1 \mathrm{Ma}$ before present. In addition, the different later reorientations of single lava blocks during their collapse from the steep inner crater wall could have been constrained by the vector data.

3. The small Monturaqui impact crater in the Atacama Desert of northern Chile represents an analogue for many other simple type craters, like Bonneville crater on Mars. The granitoid and rhyolitic target rocks have few magnetic carriers and only week magnetic anomalies. Pronounced anomalies along the crater rim indicate metre-sized unexposed remnants of the iron-bearing impactor (octahedrite).

Local mapping with a decimetre resolution, with intensities ranging from -2000 to $+6000 \mathrm{nT}$, corroborates the existence of such localised, strong, and relatively small-size $(1 \mathrm{~m})$ dipoles (iron meteorite fragments) near the surface.

4. A site within the Patagonian batholith of the southernmost Andes provides a window into deeper planetary crustal magnetic signatures. The exposed rocks include granites and mafic dykes that have been partly equilibrated at lower amphibolite facies conditions, where all primary magmatic magnetites have been transformed to iron-bearing silicates, and a later hydrothermal mineralization produced pyrrhotite as only magnetic carrier.

The freshly exposed transitions between these granites and mafic dykes have been mapped on a decimetre scale. Despite the very low magnetic contrast from 20 to $80 \mathrm{nT}$ both rock types could have been clearly distinguished. In addition, the amount of pyrrhotite, ranging from 1 to $4 \mathrm{vol} \%$, is well correlated with the positive magnetic anomalies of the dykes. This documents the potential for mapping of hydrothermal mineralization processes as well as associated gold and copper enrichments, even if the magnetic contrast is very low.

Acknowledgements. Authors acknowledge all the MOURA MetNet team; in particular, the payload electronics engineering laboratory for their work with the magnetometer and V. Apéstigue for the technical support. This work was supported by the Spanish National Space Programme (DGI-MEC) through the project AYA2011-29967-C05-01 and the Spanish National Space Program of R\&D Externalization through the project PRI-PIBUS-20111105 .

Edited by: L. Eppelbaum 


\section{References}

Acuña, M. H., Connerney, J. E. P., Wasilewski, P., Lin, R. P., Anderson, K. A., Carlson, C. W., McFadden, J., Curtis, D. W., Mitchell, D., Reme, H., Mazelle, C., Sauvaud, J. A., d'Uston, C., Cros, A., Medale, J. L., Bauer, S. J., Cloutier, P., Mayhew, M., Winterhalter, D., and Ness N. F.: Magnetic Field and Plasma Observations at Mars: Initial Results of the Mars Global Surveyor Mission, Science, 279, 1676-1680, 1998.

Alva-Valdivia, L. M., Rivas, M. L., Goguitchaichvili, A., UrrutiaFucugauchi, J., González, J.-A., Morales, I., Gómez, S., Henríquez, F., Nyström, J. O., and Naslund, H. R.: Rock-magnetic and oxide microscopic studies of the El Laco iron-ore deposits, Chilean Andes, and implications for magnetic anomaly modelling, Int. Geol. Rev., 45, 533-547, 2003.

Blaikie, T. N., Ailleres, L., Cas, R. A. F., and Betts, P. G.: Threedimensional potential field modelling of a multi-vent maardiatreme - The Lake Coragulac maar, Newer Volcanics Province, south-eastern Australia, J. Volcanol. Geoth. Res., 235-236, 7083, 2012.

Bolós, X., Barde-Cabusson, S., Pedrazzi, D., Martí, J., Casas, A., Himi, M., and Lovera, R.: Investigation of the inner structure of La Crosa de Sant Dalmai maar (Catalan Volcanic Zone, Spain), J. Volcanol. Geoth. Res., 247-248, 37-48, 2012.

Bucher, K. and Grapes, R.: Petrogenesis of metamorphic rocks, 8th Edn., Springer, Berlin-Heidelberg, 428 pp., doi:10.1007/978-3540-74169-5, 2011.

Buchwald, W.: Handbook of Iron Meteorites, Their History, Distribution, Composition, and Structure, Volume 3, University of California Press, Berkeley, USA, 1975.

Bunch, T. E. and Cassidy, W. A.: Petrographic and electron microprobe study of the Monturaqui Impactite, Contrib. Mineral. Petr., 36, 95-112, 1972.

Cassidy, J. and Locke, C. A.: The Auckland volcanic field, New Zealand: Geophysical evidence for structural and spatiotemporal relationships, J. Volcanol. Geoth. Res., 195, 127-137, 2010.

Clark, D. A.: Hysteresis properties of sized dispersed monoclinic pyrrhotite grains, Geophys. Res. Lett., 11, 173-176, 1984.

Clark, D. A.: Magnetic petrophysics and magnetic petrography: aids to geological interpretation of magnetic surveys, AGSO Journal of Australian Geology and Geophysics, 17, 83-103, 1997.

Connerney, J. E. P., Acuña, M. H., Ness, N. F., Kletetschka, G., Mitchell, D. L., Lin, R. L., and Reme, H.: Mars magnetic field Results from the Mars Global Surveyor, P. Natl. Acad. Sci. USA, 102, 14970-14975, 2005.

Dare, S. A. S., Barnes, S.-J., and Beaudfoin, G.: Did massive magnetite "lava flows" of El Laco (Chile) form by magmatic or hydrothermal processes? New constraints from magnetite composition by LA-ICP-MS, Miner. Deposita, 50, 607-617, doi:10.1007/s00126-014-0560-1, 2014.

Day, R., Fuller, M., and Schmidt, V. A.: Hysteresis properties of titanomagnetites: Grain size and composition dependence, Phys. Earth Planet. In., 13, 260-267, 1977.

Dekkers, M. J.: Magnetic properties of natural pyrrhotite. Part I: behaviour of initial susceptibility and saturation-magnetizationrelated rock-magnetic parameters in a grain size dependend framework, Phys. Earth Planet. In., 52, 376-393, 1988.
Dekkers, M. J.: Magnetic properties of natural pyrrhotite. Part II: High and low temperature behaviour of Jrs and TRM as function of grain size, Phys. Earth Planet. In., 57, 266-283, 1989.

Díaz-Michelena, M. and Kilian, R.: MOURA Martian magnetometer potential for high resolution magnetic mapping, EGU General Assembly, Vienna, Austria, 7-12 April 2013, EGU2013-1886, 2013.

Díaz-Michelena, M. and Kilian, R.: Magnetic signatures of the orogenic crust of the Patagonian Andes with implication for planetary exploration, Phys. Earth Planet. In., 248, 35-54, doi:10.1016/j.pepi.2015.08.005, 2015.

Díaz-Michelena, M., Sanz, R., Cerdán, M. F., and Fernández, A. B.: Calibration of QM-MOURA three-axis magnetometer and gradiometer, Geosci. Instrum. Method. Data Syst., 4, 1-18, doi:10.5194/gi-4-1-2015, 2015a.

Díaz-Michelena, M., Cobos Arribas, P., and Aroca Hernández-Ros, C.: Lock-in amplifiers for AMR sensors, Sensor. Actuat. APhys., 222, 149-159, 2015 b.

Direen, N. G., Pfeiffer, K. A., and Schmidt, P. W.: Strong remanent magnetization in pyrrhotite: A structurally controlled example from the Paleoproterozoic Tanmi orogenic gold province, northern Australia, Precambrian Res., 165, 96-106, 2008.

Dos Santos, E., Gattacceca, J., Rochette, P., Scorzelli, R. B., and Fillion, G.: Magnetic hysteresis properties and ${ }^{57} \mathrm{Fe}$ Mössbauer spectroscopy of iron and stony-iron meteorites: Implications for mineralogy and thermal history, Phys.e Earth Planet. In., 242, 50-64, 2015.

Dunlop, D. J.: Theory and application of the Day plot $\left(M_{r s} / M_{S}\right.$ versus $\left.H_{c r} / H_{c}\right)$, 2. Application to data for rocks, sediments, and soils, J. Geophys. Res., 107, EPM 5-1-EPM 5-15, doi:10.1029/201JB000487, 2002.

Echaurren, A., Ocampo, C., and Rocca, M. C. L.: A mathematic model for the Monturaqui impact crater, Chile, South America, 68th Annual Meteoritical Society Meeting, p. 5004, 2005.

Eppelbaum, L. V.: Quantitative Interpretation of Magnetic Anomalies from Bodies Approximated by Thick Bed Models in Complex Environments, Environmental Earth Sciences, 74, 59715988, 2015.

Eppelbaum, L. V. and Mishne, A. R: Unmanned airborne magnetic and VLF investigations: effective geophysical methodology of the near future, Positioning, 2, 112-133, 2011.

Francis, D.: Columbia Hills - An exhumed layered igneous intrusion on Mars?, Earth Planet. Sc. Lett., 310, 59-64, 2011.

Gardeweg, M. and Ramírez, C. F.: Hoja Rio Zapaleri, II Region de Antofagasta: Santiago, Chile, Servicio Nacional de Geología y Minería, Carta Geológica de Chile, 66, 89 pp., 1985.

Gobashy, M. M. and Al-Garni, M. A.: High Resolution Ground Magnetic Survey (HRGM) for determining the optimum location of subsurface dam in Wadi Nu'man, Makkah Al Mukarammah, KSA, JKAU: Earth Sci., 19, 57-83, 2008.

Grant, A. J., Arvidson, R., Bell III, J. F., Cabrol, N. A., Carr, M. H., Christensen, P., Crumpler, L., Des Marais, D. J., Ehlmann, B. L., Farmer, J., Golombek, M., Grant, F. D., Greeley, R., Herkenhoff, K., Li, R., McSween, H. Y., Ming, D. W., Moersch, J., Rice Jr., J. W., Ruff, S., Richter, L., Squyres, S., Sullivan, R., and Weitz, C.: Surficial Deposits at Gusev Crater Along Spirit Rover Traverses, Science, 305, 807-810, 2004. 
Hervé, F., Pankhurst, R. J., Fanning, C. M., Calderón, M., and Yaxley, G. M.: The South Patagonian batholith: $150 \mathrm{my}$ of granite magmatism on a plate margin, Lithos, 97, 373-394, 2007.

Hinze, W. J., Von Frese R. R. B., and Saad, A. H.: Gravity and magnetic Exploration, Principles, Practices and Applications, Cambridge University Press, Cambridge, 525 pp., 2013.

Ialongo, S., Fedi, M., and Florio, G.: Invariant models in the inversion of gravity and magnetic fields and their derivatives, Appl. Geophys., 110, 51-62, 2014.

Jonnsson, E., Troll, V. R., Högdahl, K., Harris, C., Weis, F., Nilsson, K., and Skelton, A.: Magmatic origin of giant 'Kiruna-type' apatite-iron-oxide ores in Central Sweden, Scientific Reports, 3, 1644, doi:10.1038/srep01644, 2013.

Kereszturi, G. and Németh, K.: Monogenetic Basaltic Volcanoes: Genetic Classification, Growth, Geomorphology and Degradation, in: Updates in Volcanology - New Advances in Understanding Volcanic Systems, edited by: Németh, K., InTech, 3-88, doi:10.5772/51387, 2012.

Kilian, R. and Behrmann, J. H.: Geochemical constraints on the sources of continent-related deep sea sediments and their recycling in arc magmas of the Southern Andes, J. Geol. Soc. London, 160, 57-70, 2003.

Kloberdanz, C. M.: Geochemical analysis of the Monturaqui Impact Crater, Chile, PhD thesis, University of Iowa, 2010.

Langlais, B. and Thébault, E.: Predicted magnetic signatures of Martian (de)magnetized impact craters and a statistical comparison with observations, Icarus, 212, 568-578, 2011.

L'Heureux, E., Ugalde, H., Milkereit, B., Boyce, J., Morris, W., Eyles, N., and Artemieva, N.: Using vertical dikes as a new approach to constraining the size of buried craters: An example from Lake Wanapitei, Canada, in: Large Meteorite Impacts III, edited by: Kenkmann, T., Hörz, F., and Deutsch, A., Geological Society of America Special Paper 384, 43-50, 2005.

Lillis, R. J., Robbins, S., Manga, M., Halekas, J. S., and Frey, H. V.: Time history of the Martian dynamo from crater magnetic field analysis, J. Geophys. Res.-Planet., 118, 1488-1511, doi:10.1002/jgre.20105, 2013.

Maksaev, V., Gardeweg, M., Ramírez, C. F., and Zentilli, M.: Aplicación del método trazas de fisión (fission track) a la datación de cuerpos de magnetita de El Laco e Incahuasi en el altiplano de la región de Antofagasta, Congreso Geológico Chileno 5th, Santiago, 1, B1-B23, 1988.

McEnroe, S. A., Brown, L. L., and Robinson, P.: Earth analog for Martian magnetic anomalies: remanence properties of hemoilmenite norites in the Bjerkreim-Sokndalintrusion, Rogaland, Norway, J. Appl. Geophys., 56, 195-212, 2004.

McEnroe, S. A., Fabian, K., Robinson, P., Gaina, C., and Brown, L. L.: Crustal magnetism, lamellar magnetism and rocks that remember, Elements, 5, 241-246, 2009.

Mejia, V., Opdyke, N. D., Vilas, J. F., Singer, B. S., and Stoner, J. S.: Plio-Pleistocene time-averaged field in southern Patagonia recorded in lava flows, Geochem. Geophy. Geosy., 5, Q03H08, doi:10.1029/2003GC000633a, 2004.

Morschhauser, A., Lesur, V., and Grott, M.: A spherical harmonic model of the lithospheric magnetic field of Mars, J. Geophys. Res., 119, 1162-1188, 2014.

Naranjo, J. A., Henríquez, F., and Nyström, J. O.: Subvolcanic contact metasomatism at El Laco Volcanic Complex, Central Andes, Andean Geology, 37, 110-120, 2010.
Nelson, E. P.: Suprasubduction Mineralization: Metallo-tectonic Terranes of the Southernmost Andes, in: Subduction Top to Bottom, edited by: Bebout, G. E., Scholl, D. W., Kirby, S. H., and Platt, J. P., American Geophysical Union, Washington, D. C., Geophysical Monograph, 96, 315-329, 1996.

Okuma, S., Stotter, C., Supper, R., Nakatsuka, T., Furukawa, R., and Motschka, K.: Aeromagnetic constraints on the subsurface structure of Stromboli Volcano, Aeolian Islands, Italy, Tectonophysics, 478, 19-33, 2009.

Osinski, G. R. and Pierazzo, E.: Impact cratering: Processes and products, Wiley, 330 pp., 2013.

Philpotts, A. and Ague, J.: Principles of Igneous and Metamorphic Petrology, Cambridge University Press, 684 pp., 2009.

Pilkington, M. and Grieve, R.: The geophysical signature of terrestrial impact craters, Rev. Geophys., 30, 161-181, 1992.

Robbins, S. J., Hynek, B. M., Lillis, R. J., and Bottke, W. F.: Large impact crater histories of Mars: The effect of different model crater age techniques, Icarus, 225, 173-184, 2013.

Prezzi, C., Orgeira, M., Acevedo, R., Ponce, J., Martinez, O., Rabassa, J., Corbella, H., Vásquez, C., González-Guillot, M,. and Subías, I.: Geophysical characterization of two circular structures of Bajada del Diablo (Argentina): indication of impact origin, Phys. Earth Planet. In., 192-193, 21-34, 2012.

Sánchez, I. and Cassidy, W.: A previously undescribed meteorite crater in Chile, J. Geophys. Res., 71, 4891-4895, 1966.

Schalamuk, I. B., Zubia, M., Genini, A., and Fernández, R. R.: Jurassic epithermal Au-Ag deposits of Patagonia, Argentina, Ore Geol. Rev., 12, 173-186, 1997.

Scott, E. R. D. and Fuller, M.: A possible source for the Martian crustal magnetic field, Earth Planet. Sc. Lett., 220, 83-90, 2004.

Sillitoe, R. H. and Burrows, D. R.: New field evidence bearing on the origin of the El Laco magnetite deposits, Northern Chile, Econ. Geol., 97, 1101-1109, 2002.

Skewes, M. A. and Stern, C. R.: Petrology and geochemistry of alkali basalts and ultramafic inclusions from the Pali-Aike Volcanic Field in southern Chile and the origin of the Patagonian Plateau lavas, J. Volcanol. Geoth. Res., 6, 3-25, 1979.

Ugalde, H., Valenzuela, M., and Milkereit, B.: An integrated geophysical and geological study of the Monturaqui impact crater, Chile, Meteorit. Planet. Sci., 42, 2153-2163, 2007.

Ukstins Peate, I., Kloberdanz, C., Peate, D. W., Chung Wan, L., Cabrol, N., Grin, E., Piatek, J., and Chong, G.: Non-modal melting of target rocks to produce impactite at Monturaqui Crater, Chile, 41st Lunar and Planetary Science Conference, 1-5 March 2010, Houston, Texas, 2010.

Urrutia-Fucugauchi, J., Trigo-Huesca, A., and Pérez-Cruz, L.: Magnetic links among lava flows, tuffs and the underground plumbing system in a monogenetic volcano, derived from magnetics and paleomagnetic studies, Phys. Earth Planet. In., 212-213, 10-18, 2012.

Velasco, F. and Tornos, F.: Insights on the effect of hydrothermal alterartion in the El Laco magnetitre deposits, Revista de la Sociedad Espanola de Mineralogía, 16, 2 pp., 2012.

Zhao, X., Riisager, P., Antretter, M., Carlut, J., Lippert, P., Liu, Q., Galbrun, B., Hall, S., Delius, H., and Kanamatsu, T.: Unraveling the magnetic carriers of igneous cores from the Atlantic, Pacofoc, and the southern Indian oceans with rock magnetic characterization, Phys. Earth Planet. In., 156, 294-328, 2006. 